\title{
Performance in psychiatry undergraduate finals
}

\section{The influence of gender and nationality}

\author{
Rachael Cullivan, Siobhan Rooney, Gabrielle Kelly and Noel Walsh
}

\begin{abstract}
Aims and method This study investigated the effects of gender and nationality on performance in various aspects of the undergraduate final examination in psychiatry. Results in all sections of the final examination were analysed in the case of 140 students from the same year.

Results There were no statistically significant differences between performances by males and females, however non-nationals performed less well in all aspects of the examination.

Clinical implications Teaching programmes need to Identify which aspects of the undergraduate course cause particular difficulty for non-nationals. This information would usefully inform future developments in undergraduate teaching.
\end{abstract}

Earlier research suggests that female undergraduates perform better than male undergraduates in medical faculty examinations, but these differences have not been found to apply to all specialities (Norcini et al, 1985). Scott et al (1993) found that in the area of psychiatry females performed slightly better than males in the clinical attachment. Gender-related differences were noted by Fabrega et al (1994) in their study of factors influencing medical students' learning of psychopathology assessment during psychiatric clerkship. Female medical students showed a significant improvement in accuracy of assessment of psychopathology during the clerkship, while their male counterparts actually showed a significant reduction in accuracy. Some of these differences have been attributed to the more favourable attitude of females toward the behavioural sciences and psychiatry. Other studies have also found differences in performance in undergraduate psychiatry between males and females, but the differences were not significant (Keitner et al, 1984; Alexander \& Eagles, 1988).

Our subjective impressions suggested that females were performing better in their psychiatry attachment at our centre, and obtaining higher marks for their 'continuous assessment'. Previous studies have indicated that males may be better at the more 'scientific' specialities
(Norcini et al, 1985), while females perform better in psychiatry because of better interpersonal skills (Keitner et al, 1984). We hypothesised that females would perform better overall, but that the male students would perform best in the more 'scientific' multiple choice question (MCQ) paper in the final examination. We also took this opportunity to investigate how well non-nationals were achieving within the framework of the present curriculum. In recent years there has been an increase in the number of students from other countries who choose to study medicine in Ireland. Our subjective impression was that their performance in psychiatry was hampered by difficulties with language, and by varying cultural beliefs surrounding psychiatric illness. We hypothesised that the non-national students would perform less well in the areas of the final examination which required the greatest understanding of language, that is the essay and MCQ papers and the oral examination.

\section{The study}

The students of University College Dublin spend their clinical attachment in psychiatry with the liaison psychiatry departments of one of two general hospitals in Dublin city. The clinical attachment is for a period of eight weeks, and students are awarded $10 \%$ of their final mark in psychiatry on the basis of continuous assessment during this time. The final examination consists of an MCQ paper which contributes $10 \%$ to the final mark; an essay paper which contributes 30\%; and an oral examination which contributes $50 \%$. These marks are combined with those obtained from continuous assessment, and an overall mark of $50 \%$ or more is required to pass. The MCQ paper marking is anonymised but the candidate's name is known to the examiner in the other parts of the examination. For the purposes of the oral examination the candidate is examined by two psychiatrists, one of whom asks questions on 
general psychiatric topics, while the other presents the candidate with a case vignette to discuss. A consensus mark is then awarded.

For the purposes of this study, the results of the final examination in psychiatry from a single year of final medical students were analysed. These results were compared with regard to gender and nationality using the SAS statistical package. Differences between males and females and nationals and non-nationals were ascertained using $t$-tests of variance (Satterthwite's method).

\section{Findings}

The results of 140 students who sat the final medical examination in the year of the study were analysed. Fifty-six were male and 84 were female. Irish nationals accounted for 110 of the students and 30 were non-nationals. There were no statistically significant differences between males and females with regard to scores in any part of the examination. Also, although the difference was not significant, females scored on average better than their male colleagues in the MCQ paper, which was contrary to our expectations (Table 1).

When results were compared according to whether the students were nationals or nonnationals, non-nationals performed less well than nationals in all areas of the examination. The differences were statistically significant in all aspects of the examination with the exception of the continuous assessment (Table 2).

Because of the difference noted between nationals and overseas students, a further analysis of results within a more homogeneous group of Irish nationals was carried out (Table 3). Once again there were no statistically significant differences between mean scores according to gender.

Table 1. Average scores in different areas of the examination according to gender

\begin{tabular}{lllll}
\hline & $\begin{array}{l}\text { Mean female score } \\
\mathbf{9 5 \%} \text { confidence interval), } \\
\text { Form of assessment }\end{array}$ & $\begin{array}{l}\text { Mean male score } \\
\mathbf{9 5 \%} \text { confidence interval), } \\
\mathbf{n = 5 6}\end{array}$ & $\mathbf{T}$ & $\mathbf{P}$ \\
\hline Continuous assessment & $63.4(61.4-65.4)$ & $51.2(59.1-63.3)$ & -1.5 & 0.13 \\
MCQ & $57.1(54.7-59.5)$ & $55.7(54.6-56.0)$ & -1.2 & 0.22 \\
Essay paper & $55.8(54.9-56.7)$ & $55.3(53.9-56.7)$ & -0.04 & 0.96 \\
Oral examination & $56.1(54.8-57.4)$ & $56.0(54.6-57.3)$ & -0.8 & 0.40 \\
Final mark & $56.8(55.7-57.8)$ & -0.9 & 0.35 \\
\hline
\end{tabular}

Degrees of freedom $=138(83,55)$.

Table 2. Average scores in different areas of the examination in nationals and non-nationals

\begin{tabular}{lllll}
\hline Form of assessment & $\begin{array}{l}\text { Irish nationals mean score } \\
\text { (95\% confidence inferval), } \\
n=110\end{array}$ & $\begin{array}{l}\text { Non-nationals mean score } \\
(\mathbf{9 5 \%} \text { confidence interval), } \\
n=30\end{array}$ & $\boldsymbol{T}$ & $\mathbf{P}$ \\
\hline Continuous assessment & $63.1(61.5-64.7)$ & $60.4(57.0-63.8)$ & 1.5 & 0.13 \\
MCQ & $57.3(55.3-59.3)$ & $51.7(46.7-56.7)$ & 2.3 & $0.02^{*}$ \\
Essay paper & $56.5(55.9-57.1)$ & $52.8(51.2-54.4)$ & 4.5 & $0.00001^{* * *}$ \\
Oral examination & $56.5(55.5-57.5)$ & $53.1(50.5-55.7)$ & 3.0 & $0.0029^{*}$ \\
Overall mark & $57.3(56.5-58.1)$ & $53.7(52.5-55.9)$ & 3.7 & $0.003^{*}$ \\
\hline
\end{tabular}

Degrees of freedom $=138(109,29)$.

${ }^{\star} P<0.05$.

$* * P<0.001$.

Table 3. Average scores in different areas of the examination according to gender in Irish nationals

\begin{tabular}{|c|c|c|c|c|}
\hline Form of assessment & $\begin{array}{l}\text { Irish females mean score } \\
(95 \% \text { confidence interval), } \\
n=69\end{array}$ & $\begin{array}{l}\text { Irish males mean score } \\
\text { ( } 95 \% \text { confidence interval), } \\
n=41\end{array}$ & $\boldsymbol{T}$ & $\boldsymbol{P}$ \\
\hline $\begin{array}{l}\text { Continuous assessment } \\
\text { MCQ } \\
\text { Essay paper } \\
\text { Oral examination } \\
\text { Overall mark }\end{array}$ & $\begin{array}{l}63.6(61.6-65.6) \\
57.9(55.5-60.3) \\
56.4(55.6-57.2) \\
56.6(55.4-57.8) \\
57.4(56.4-58.4)\end{array}$ & $\begin{array}{l}62.3(59.7-64.9) \\
56.2(52.0-60.4) \\
56.7(55.5-57.9) \\
56.3(54.9-57.7) \\
57.1(55.7-58.5)\end{array}$ & $\begin{array}{r}-0.76 \\
-0.78 \\
0.38 \\
-0.31 \\
-0.32\end{array}$ & $\begin{array}{l}0.44 \\
0.43 \\
0.70 \\
0.75 \\
0.75\end{array}$ \\
\hline
\end{tabular}

Degrees of freedom $=108(68,40)$. 


\section{Comment}

Contrary to our expectations based on previous studies and our own subjective impression, there was no statistically significant difference between male and female students with regard to the final medical examination in psychiatry at our centre. In fact the average scores achieved by females were non-significantly higher than those of their male colleagues in all aspects of the examination including the more 'scientific' MCQ. This was also contrary to our expectations, as we had expected the males to perform better in this section of the examination. It may be that the aspects of psychiatry in which females outperform their male colleagues, such as the rating of psychopathology as noted by Fabrega et al (1994), are not specifically examined in any of the assessment formats used. The ability to elicit psychopathology, for example, can only really be assessed within the framework of the continuous assessment, the aspect of the examination in which there was the greatest difference in scores between genders. The areas in which females perform best might be counterbalanced by superior performances by males in other areas, such as the more exact and 'scientific' aspects. This argument is hardly supported by the similar scores by both genders in the MCQ. It is also possible that the use of only a single year of students has resulted in a type II error, as previous studies which have found gender differences have tended to group students from several years, or several centres (Scott et al. 1993). The marked differences in scores between nationals and non-nationals may also have influenced our findings. However, a further analysis of scores with overseas students removed still failed to find significant differences between the genders. Hence it would appear that males are joining their female colleagues at the top of the class.

Such highly significant differences between results, both overall and in various aspects of the examination, of non-nationals compared with nationals, were unexpected. We feel this may be related to difficulties with the very much language-based nature of the speciality. This is supported by the finding of the most highly significant differences in the areas of the essay paper and oral examination, while the area in which the non-nationals scored best is the continuous assessment. This is very much based on the opinion of a consultant or tutor to whom the candidate is well known and who may be able to take into account any difficulties the student has with the language of the speciality. As marking in the examination is anonymised for the purpose of the MCQ only, the possibility of bias must be considered. The fact that overseas students score significantly worse in all areas of the examination, including the anonymised MCQ, but with the exception of the continuous assessment in which nationality is evident, does not support this.

At our centre we found males were achieving as well as females in the final examination in psychiatry, both in the class as a whole, and within the group of Irish students. Some earlier studies suggest that males tend to have a less positive attitude towards psychiatry (Wilkinson et al, 1983), which may contribute to underachievement in the subject as undergraduates, with consequences for subsequent interest in, and recruitment to the speciality (Scott et al, 1993). As we found the males to be achieving as well as females, it may be that the negative attitudes are being altered by changes in the teaching and practice of psychiatry, for example the increased emphasis on the biological and scientific'. Although it is not possible to be certain why, the fact that the genders are performing equally well is encouraging given the recent fears expressed about the future of psychiatry and the prospect of falling recruitment. The fact that students from overseas were found to have fared statistically significantly worse is worrying. The area in which they fared best was in the continuous assessment, while the essay paper appeared to present the most difficulties for them. As this suggests languagerelated difficulties it has important implications for the structure of the teaching programme in relation to this group.

\section{References}

Alexander, D. A. \& Eagles, J. M. (1988) Change in attitudes towards psychiatry among medical students - correlation of shift with academic performance. Medical Education, 24, 452-460.

Fabrega. H., Ulrich, R. \& Keshavan, M. (1994) Gender differences in how medical students learn to rate psychopathology. Joumal of Nervous and Mental Disease, 182, 471-475.

KeITNER, G., BALDWIN, L. \& MCKENDELL, M. (1984) Gender and psychiatric clerkship performance. Canadian Journal of Psychiatry. 29. 327-329.

NORCINI, J., FLETCHER. S., QUIMBY, B.. et al (1985) Women candidates on the American Board of Internal Medicine certifying examination 1970-1982. Annals of Internal Medicine, 102, 115-118.

SCOTT, J., AllaRDYCE, J. \& FERRIER, N. (1993) Gender differences in undergraduate performance in psychiatry. Psychiatric Bulletin. 17, 599-600.

WILKINSON, D. G., GREER, S. \& TOONE, B. (1983) Medical students' attitudes to psychiatry. Psychological Medicine, 13, 185-192.

*Rachael Cullivan, Senior Registrar, St Davnet's Hospital, Monaghan, Ireland: Siobhan Rooney, Senior Registrar, University College Hospital, Cork; Gabrielle Kelly, Department of Statistics, University College Dublin; and Noel Walsh, Professor of Clinical Psychiatry. St Vincent's Hospital, Dublin 4

*Correspondence 